\title{
Longitudinal dispersion and unsteady salinity intrusion in estuaries
}

\author{
by Donald R. F. Harleman \\ Professor of Civil Engineering and Director, \\ R. M. Parsons Laboratory for Water Resources and Hydrodynamics, \\ M.I.T., Cambridge, Massachusetts \\ and M. Llewellyn Thatcher \\ Assistant Professor of Marine Science, Southampton College, Southampton, N.Y.
}

\section{Introduction}

The distribution of salinity in a tidal estuary is a continuous function of space and time. The major factors determining a particular salinity distribution are the estuary geometry, the tidal motion within the estuary (as governed by the varying tidal elevation at the ocean entrance), the fresh water inflows, the density difference between fresh and ocean water, and possibly, wind and Coriolis effects. Depending on the relative magnitude of these quantities, varying degrees of vertical and lateral stratification of salinity are possible. In a real estuary all of the above quantities are time varying and "steady state" conditions cannot be assumed to exist.

Analytical and experimental studies of salinity intrusion in estuaries have been made by many investigators during the past 25 years. Most of the mathematical models which have been developed are descriptive rather than predictive. That is, the models contain one or more empirical features, based on observed field or laboratory data, which make it difficult or impossible to predict the effect on the salinity distribution of changes in the estuary regime. Changes for which it is desirable to have a predictive capability include the effect of channel deepening and changes in the fresh water inflow due to upstream river flow regulation or fresh water diversions.

A general analytical description of salinity distribution in an estuary would require an unsteady, three-dimensional approach. Although the governing differential equations for the unsteady, three-dimensional problem (i.e. continuity, momentum and conservation of mass) are known, numerical solution techniques have not progressed to the point at which the computations can be handled efficiently. Even if the computational problems were overcome, there is almost no information on the three-dimensional spatial and temporal functions for turbulent eddy and mass diffu- sivities which would be needed for mathematical models having predictive capability.

The objective of this paper is to review the difficulties in the development of mathematical models for salinity distribution and to present the results of a recent mathematical model developed for the prediction of one-dimensional, unsteady salinity intrusion in variable area estuaries.

\section{Review of previous investigations}

Mathematical modeling involves a number of steps: (1) formulation of the governing equations; (2) consideration of the boundary and initial conditions necessary for solution; (3) specification of functional relationships for turbulent diffusion or dispersion coefficients in the governing equations; and (4) development of solution techniques. The following is not intended to be a complete review of the literature but rather a discussion of the difficulties encountered in the sequence of steps enumerated above. For simplicity, the discussion will be limited to one dimensional, mathematical models for variable area estuaries in which the salinity distribution $s=g(x, t)$.

\section{Formulation}

The most general one-dimensional equations for unsteady tidal motion and salinity distribution are the following:

Continuity Equation:

$$
b \frac{\partial h}{\partial t}+\frac{\partial Q}{d x}-q=0
$$


Momentum Equation:

$$
\begin{gathered}
\frac{\partial Q}{\partial t}+\frac{\partial(Q u)}{d x}+g \frac{\partial h}{\partial x} A+g \frac{A d_{c}}{\rho} \frac{\partial \rho}{\partial x} \\
+\frac{g Q|Q|}{A C^{2} R_{h}}=0
\end{gathered}
$$

Salt Balance Equation:

$$
\frac{\partial\left(A_{t} s\right)}{\partial t}+\frac{\partial(Q s)}{d x}=-\frac{\partial}{\partial x}\left(A_{t} E \frac{\partial s}{\partial x}\right)
$$

Equation of State:

$$
\rho=0.75 s+1,000
$$

where:

$$
\begin{aligned}
b= & \text { total surface width; } \\
h= & \text { depth from water surface to horizontal datum; } \\
Q= & \text { cross-sectional discharge }(Q=A u) \\
q= & \text { lateral inflow per unit length; } \\
u= & \text { longitudinal velocity averaged over the cross- } \\
& \text { seotion of the conveyance area; } \\
A= & \text { conveyance area or area of primary longitudinal } \\
& \text { flow; } \\
g= & \text { acceleration of gravity; } \\
d_{c}= & \text { distance from the water surface to the centroid } \\
& \text { of the cross-section; } \\
\rho= & \text { density of water; } \\
R_{h}= & \text { hydraulic radius of conveyance area; } \\
C= & \text { Chezy coefficient; } \\
A_{t}= & \text { the total area of the cross-section including that } \\
& \text { corresponding to storage areas; if any; } \\
s= & \text { salinity averaged over the total cross-section, in } \\
& \text { parts per thousand (ppt); } \\
E= & \text { longitudinal dispersion coefficient. }
\end{aligned}
$$

All of the above quantities (except $g$ ) are functions of longitudinal position $x$ and time $t$, where intervals of time are small compared to a tidal period.

The continuity equation (1) and the momentum equation (2) are essentially in the form used by Harleman and Lee [5] to describe the unsteady tidal hydraulics of estuaries and canals. An additional term in the momentum equation includes the effect of the longitudinal density gradient due to salinity. This term, $g A\left(d_{c} / \rho\right)(\partial \rho / \partial x)$, couples the two equations describing the tidal hydraulics to the salt balance equation through the simplified equation of state.

The one-dimensional salt balance equation (3) is obtained from the spatially integrated three-dimensional convectivediffusion equation for turbulent flow. (Okubo [10]; Holley and Harleman [7]). The longitudinal dispersion coefficient $E$ includes the turbulent diffusivity and the dispersive effect produced by salinity and velocity variations over the cross section $A$.

Stigter and Siemons [12] used the salt balance equation (3) and the tidal hydraulics equations ( 1 and 2 ) in coupled form to calculate salinity intrusion throughout a tidal cycle in a constant width representation of the Rotterdam Waterway with constant fresh water inflow. A finite difference formulation was used for the calculations.

A number of early investigators simplified the analytical problem by averaging the salt balance equation over a tidal period. The tidal-time-average form of Equation (3) is:

$$
\bar{A} \frac{\partial \bar{s}}{\partial t}+\bar{A} U_{f} \frac{\overline{d s}}{\partial x}=\frac{\partial}{\partial x}\left(\bar{A} E^{T A} \frac{\partial \bar{s}}{\partial x}\right)
$$

where $\bar{s}$ and $\bar{A}$ are the salinity and area averaged over a tidal period, $U_{f}$ is the average cross-sectional velocity due to fresh water and $E^{T A}$ is the corresponding tidaltime-average dispersion coefficient. Arons and Stommel [1] assumed that steady state conditions prevailed in successive tidal cycles (i.e. $\partial \bar{s} / \partial t=0$ ) and that the cross-sectional area, $\vec{A}$ was independent of $x$. Under these assumptions Equation (5) reduces to a second order, ordinary differential equation:

$$
U_{f} \frac{d \bar{s}}{d x}=\frac{d}{d x}\left(E^{T A} \frac{d \bar{s}}{d x}\right)
$$

Pritchard [11] and Boicourt [3] used Equation (5) to describe seasonal salinity changes in the Delaware and Chesapeake estuaries.

A second method of simplifying the analytical formulation is known as the "slack-tide" approximation. In this approach Equation (3) is assumed to describe the salinity distribution only at times of slack tide. The terminology high water slack is used to indicate the time of zero tidal discharge during the change from flood to ebb tide and low water slack the change from ebb to flood. It was recognized that by setting $Q=0$, the advective term $\partial(Q s) / \partial x$ in Equation (3) is eliminated and this would result in a loss of the entire flushing effect due to the fresh water flow $Q_{f}$. Therefore, the non-tidal advective velocity due to fresh water is retained and the resulting salt balance equation is:

$$
A \frac{\partial s}{\partial t}+A U_{f} \frac{\partial s}{\partial x}=\frac{\partial}{\partial x}\left(A E^{s L} \frac{\partial s}{\partial x}\right)
$$

wherein the salinity $s\left(x, t_{S L}\right)$ is the salinity at slack tide and $E^{S L}$ is the corresponding longitudinal dispersion coefficient for this approximation. Ippen and Harleman [9] and Harleman and Abraham [4] used the steady state form $\partial s / \partial t=0$ of Equation (7).

Both simplifications described above eliminate the need for the continuity and momentum equations for tidal velocity and discharge. In Equations (5), (6) and (7) the velocity $U_{f}$ is given by the fresh water inflow $Q_{f}$ and the estuary geometry.

\section{Boundary and initial conditions}

In many cases the question of whether a given mathematical model is descriptive or predictive depends upon the way in which the boundary conditions are treated. Mathematical models which include the tidal dynamics Equations (1) and (2) require boundary and initial conditions for the tidal motion as well as for salinity. At the downstream, or ocean boundary, of an estuary, it is usually convenient to specify the ocean tidal condition, that is, the water surface elevation as a function of time. At the upstream end of the estuary, usually taken as the head of tide, the discharge is specified. For a closed-end estuary in which the head 
of tide is determined by a physical obstruction such as a dam or natural fall line, the discharge is set equal to zero and all inflows inchuding the fresh water inflow at the head of tide are treated as steady or time-varying lateral inflows. In an open-end estuary the head of tide is determined by the location at which tidal effects become insignificant and the river discharge is specified as a function of time. Because of the rapid response of the tidal hydraulics equations to imposed boundary conditions, exact specification of initial conditions is not required. The solution can be started at $t=0$ with all water surface elevations at mean sea level (MSL) and with zero discharge.

Salinity boundary conditions, particularly at the downstream end, are more difficult than the tidal conditions. The upstream boundary condition is usually specified as $\partial s / \partial x=0$ for both closed and open end estuaries. The difficulty with the downstream or ocean boundary condition is illustrated in Figure 1 which shows the longitudinal salinity distribution at various times in a tidal cycle: high water slack (HWS), low water slack (LWS) and the tidal-time-average (TA).

Stigter and Siemons [12] calculated longitudinal salinity distributions throughout a tidal cycle by assuming that the salinity variation with time at the ocean boundary was known for a constant fresh water inflow at the head of the estuary. The resulting distributions agreed well with observations, however the model cannot be considered to be predictive since the salinity boundary condition at the ocean entrance would vary with any change in the fresh water inflow.

Earlier investigators (e.g. Pritchard [11]) using the tidaltime-average (TA) form of the salt balance equation (5) assumed the salinity at the ocean boundary to be a constant equal to the ocean salinity, $s_{0}$. This amounts to an artificial constraint since changes in fresh water inflow must be reflected in variations in the time-average salinity at the ocean boundary.

Ippen and Harleman [9] used the slack-tide approximation (Eq. 7) in analyzing twenty different salinity flume tests (rectangular cross-section) conducted at the Waterways Experiment Station. Fresh water inflow, ocean tidal range and roughness were the major parameters changed in these tests. The boundary condition was imposed at low water slack by assuming that ocean salinity $s_{0}$ was reached at a distance $x=-B$ seaward of the entrance at $x=0$. The distance $B$ was determined for each of the W.E.S. tests and a dimensionless empirical correlation was found between $B$ and a dimensionless number defining the degree of salinity stratification as a function of fresh water discharge and ocean tidal range. This boundary condition eliminates the artificial constraint mentioned above, however the empirical correlation is limited to estuaries of constant width.

\section{Longifudinal dispersion}

The term on the right-hand side of Equation 3 includes turbulent diffusivity associated with the temporal average of turbulent fluctuations and the dispersive effect associated with the spatial integration, over the cross-section, of the product of local velocity and salinity. The latter effect completely dominates the former. The dispersion

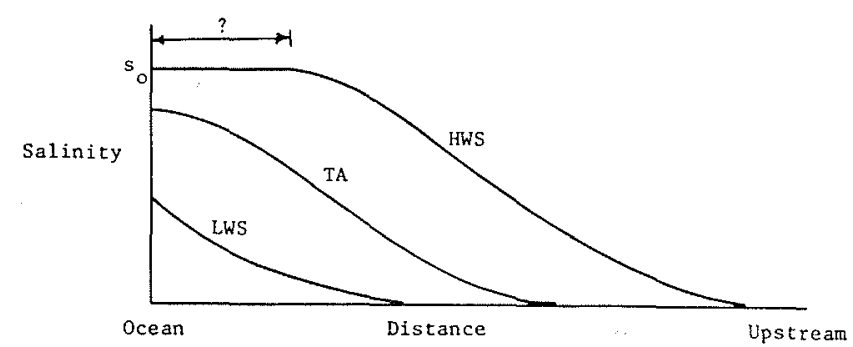

1/ Typical salinity distributions at high water slack (HWS) low water slack (LWS) and time average salinity over one tidal cycle (TA).

coefficient represents a combination of spatial variations produced by boundary shear and internal circulation induced by density (salinity) gradients. Taylor [14] and others have given quantitative relationships for boundary shear induced dispersion; however, no analytical relations have been developed for the effects of density stratification.

In a conservation of mass equation dispersion is fundamentally the result of an incomplete specification of the advective mass transport. The magnitude and variation of a dispersion coefficient depends on the formulation of the advective term in the mass transport equation. In other words, $E$, in Equation (3) is not equal to $E^{T A}$ in Equation 5 since the terms describing the advective mass transport, $\partial(Q s) / \partial x$ in Equation (3) and $A U_{f}(\partial \bar{s} / \partial x)$ in Equation (5), are radically different. Some insight into the dependence of the longitudinal dispersion coefficient on the formulation of the mass transport equation can be gained by the following analysis.

The steady-state, tidal-time-average formulation of the salt balance equation is adopted and Equation (6) is integrated with respect to $x$,

$$
U_{f} \bar{s}=E^{T A} \frac{d \vec{s}}{d x}
$$

the constant of integration being zero from the condition that at large $x$ (in the upstream direction) $d \bar{s} / d x \rightarrow 0$ and $\bar{s} \rightarrow 0$. If the fresh water velocity $U_{j}$ and the average salinity distribution over a tidal cycle is known, Equation (8) can be used to calculate $E^{T H}$ as a function of $x$. An equation similar to Eq. (8) can be obtained by integrating the steady state form of Equation (7) for the slack tide approximation,

$$
U_{f} s=E^{s L} \frac{d s}{d x}
$$

and values of $E^{S L}$ can be obtained if the salinity distribution is known at high and low water slack conditions. The functional relation between $E^{S L}$ and $x$ will be different from $E^{T A}$ and $x$ because the slack tide salinity distributions are displaced from the time average values. This is illustrated in Figure 2 which shows various dispersion coefficients calculated from the same set of data.

Figure 2 also shows the difficulty of developing a predictive model in which the longitudinal dispersion coefficient is assumed to be a unique function of $x$. Any change in the fresh water inflow will shift the salinity distribution up or down the estuary and change the func- 
tional dependence. Ippen and Harleman [9] circumvented this difficulty by adopting the following dispersion relationship for the salinity distribution at low water slack

$$
E^{S L}=\frac{E_{0}{ }^{S L} B}{x+B}
$$

where the parameter $B$, previously defined, depends on the magnitude of the fresh water discharge and $E_{0} S L_{L}$ is the dispersion coefficient at $x=0$ (the ocean entrance).

If Equation (10) is substituted into Equation (9) and integrated with respect to $x$, the following equation for the salinity distribution at low water slack is obtained,

$$
s / s_{0}=\exp \left[\frac{-U_{f}}{2 E_{0}{ }^{S L} B}(x+B)^{2}\right]
$$

where the boundary condition $s=s_{0}$ at $x=-B$ has been used. Equation (11) has the form of a Gaussian curve which closely approximates the longitudinal distribution of salinity in many estuaries. Using the W.E.S. salinity flume data, Harleman and Abraham [4] showed that the two parameters $E_{0} S L$ and $B$ could be correlated in a dimensionless manner with an estuary number:

$$
I E=\frac{P_{t} I F_{0}^{2}}{Q_{f} T}
$$

expressing the degree of stratification. In Equation (12),

$$
P_{t}=\text { tidal prism (the volume of sea water entering }
$$
the estuary on the flood tide);

$I F_{0}=$ Froude number, $u_{0} / \sqrt{g h}, u_{0}$ being the maximum flood tide velocity and $h$ the mean depth of the estuary;

$Q_{f}=$ fresh water discharge;

$T=$ tidal period.

It was shown that these correlations conld be successfully used to predict salinity intrusion in the Rotterdam Waterway. It should be noted, however, that Equation (11) and the correlations developed from the W.E.S. flume data can be applied only to estuaries of constant width with constant fresh water inflow.

\section{Solution techniques}

The formulations based on the tidal-time-average and slack-tide approximations were developed for analytical convenience prior to the advent of high speed computers. Difficulties in the treatment of boundary conditions and in the functional relations for dispersion coefficients have been reviewed. Further progress in the development of predictive models for unsteady conditions in variable area estuaries requires a return to the fundamental equations describing the unsteady, non-uniform flow including the coupling between the continuity, momentum and salt balance equations. It is obvious that the solution to this set of non-linear, second order, partial differential equations will require numerical solution techniques.

\section{A predictive model for unsteady salanity intrusion in variable area estuaries}

The development of the model is summarized in the same format as used in the review of previous investigation, i.e., formulation, boundary and initial conditions, dispersion relationship and solution technique. A detailed development is given by Thatcher and Harleman [15]

\section{Formulation}

The model is formulated in terms of the set of general one-dimensional unsteady, non-uniform flow equations for continuity, longitudinal momentum and salt balance [Equations (1) (2) (3) (4)]. The coupling of the equations, together with the inputs and outputs is shown in the diagram of Figure 3 . 'The model describes «instantaneous» conditions in the sense that the time increment is large enough to smooth turbulent fluctuations of velocity and salinity but is small compared to the tidal period.

\section{Boundary and initial conditions}

Solution of the set of partial differential equations requires that information about the dependent variables be given at the boundaries. The surface elevation as a function of time at the downstream end of the estuary and the inflow as a function of time at the head of the estuary are sufficient boundary conditions for the solution of the tidal dynamics Equations (1) and (2).

The salt balance Equation (3), being of second order, requires salinity information at both end of the estuary. There are two possible boundary conditions at the upstream end of the estuary. The salinity can be set equal to zero, or zero flux of salt can be specified across the upstream boundary $(\partial s / \partial x=0)$. Both are valid conditions, however the flux specification is more general as it permits the study of closed-end estuaries where the salinity may reach the upstream end.

The specification of a salinity boundary condition at the ocean or downstream end of the estuary is one of the principal problems treated in this study. It would be desirable to have a schematization which permitted a study of the estuary from its upstream end to a point far at sea so that the boundary salinity could be specified as a constant equal to the ocean salinity, $s_{0}$. Unfortunately this is usually not possible in a one-dimensional model as the ocean cannot be represented in one dimension. When the ocean-estuary connection is that of an entrance suddenly opening into the ocean (as in the Rotterdam Waterway) it is clear that the ocean cannot be part of the one-dimensional model. In this case the physical location of the ocean boundary is readily defined, but this does not simplify the specification of the salinity boundary condition. During the ebb flow the salinity at the ocean entrance will reflect upstream conditions, and when the flow reverses the salinity will not immediately become ocean salinity but will reach the ocean salinity in a manner depending upon the longshore currents. Significant variations in salinity over the tidal cycle at the ocean entrance can be expected in estuaries of this configuration. 
In contrast to the estuary described above is the configuration wherein the estuary gradually widens at it reaches the ocean (as in the Delaware and Thames estuaries). In this case the location of the ocean boundary depends on practical considerations of schematization. If it is possible to carry the one-dimensional schematization sufficiently far downstream, the variation in salinity throughout the tidal cycle will be small. However, the salinity at the ocean entrance cannot be constant throughout the tidal period because fresh water must leave the estuary during some portion of the tidal period and during this portion the average salinity at the ocean boundary crosssection will be decreased.

As the model treats the variation in salinity within a tidal cycle, the boundary condition must apply at ali times during each tidal cycle. The approach is to divide each tidal cycle in two portions, according to the direction of flow at the ocean entrance, and to apply a boundary condition for each portion. At each time step the numerical model calculates the magnitude and direction of the discharge at the ocean end, thus providing the necessary criterion for applying either boundary condition.

The salinity at the ocean boundary during flood flow $[Q(O, t)>0]$ is approximated by setting it equal to the ocean salinity, $s_{0}$. During ebb flow $[Q(O, t)<0]$ the solution to the finite difference analog of Equation (3) is continued by making continuous mass balances on the downstream element. In performing these mass balances the dispersive flux, $A_{t} E(\partial s / \partial x)$, on the downstream side of the element is approximated by using the gradient as evaluated at the upstream side of the element. As this approximation continues only during seaward or ebb flow it does not result in the accumulation of errors.

At the end of ebb flow the salinity will be below that of the ocean salinity, $s_{0}$. Physically, it cannot return to $s_{0}$ instantaneously as the flood flow begins. A linear interpolation in time is employed to specify the salinity during the transition from its value at the end of ebb flow to the maximum value $s_{0}$. This transition period depends on long shore currents in the ocean adjacent to the estuary entrance. Fortunately, the model is not very sensitive

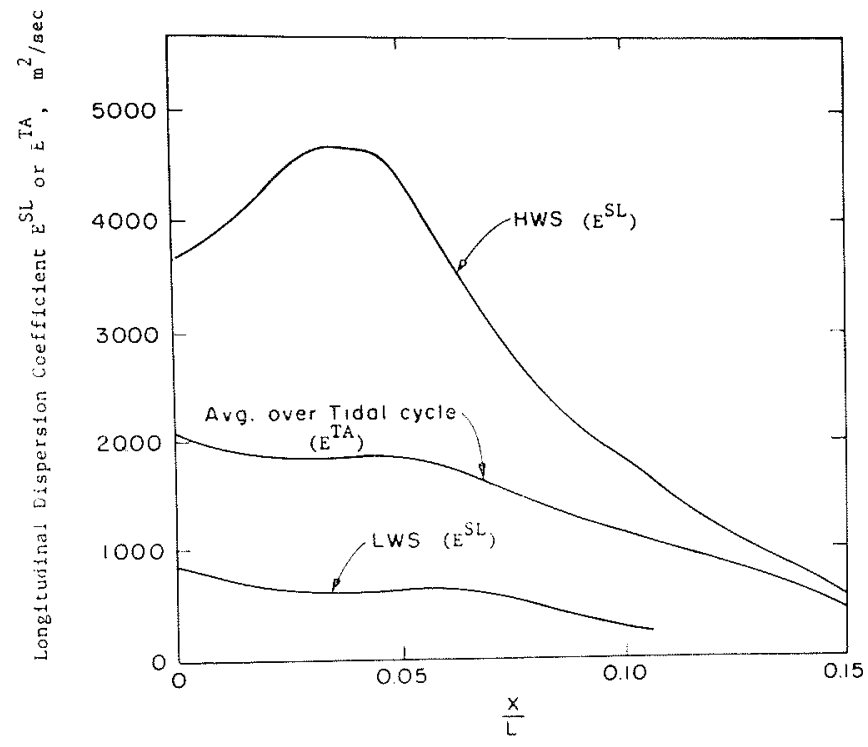

2/ Longitudinal dispersion coefficients calculated from salinity distribution data at HWS and LWS (Eq. 9) and from salinity averaged over a tidal cycle (Eq. 8) (data from ref. 12).

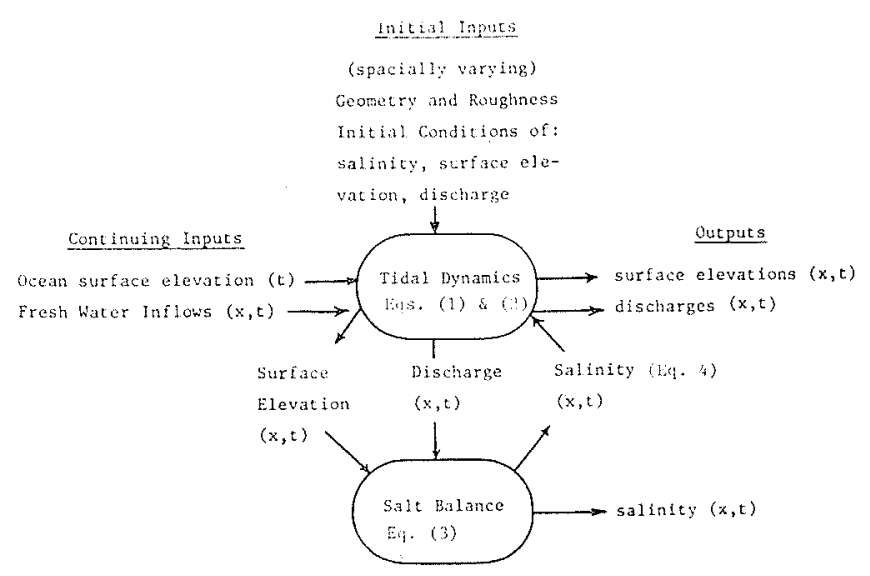

3/ Genera: formulation of numerical model.

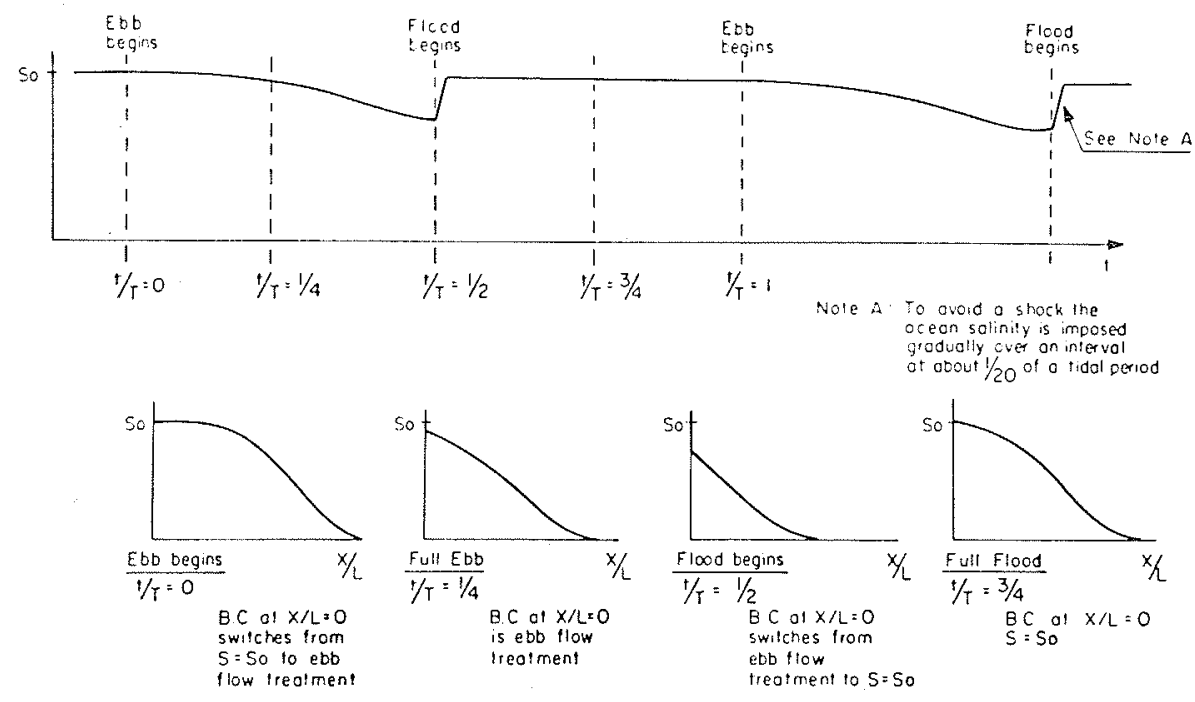

4/ Ocean boundary conditions throughout a tidal cycle. 
to the choice of this parameter and a value equal to $1 / 20$ of a tidal period has been used in a number of studies. Figure 4 shows, in graphic form, the various aspects of this boundary condition throughout a typical tidal cycle.

Initial conditions must be specified for the salinity and for the water surface elevations and the discharges. Due to the rapid convergence of the tidal hydraulics equations it is feasible to generate initial conditions for water surface elevation and discharge. This is done by assuming an approximate salinity distribution and by beginning the calculations with discharges equal to zero and elevations at mean sea level at a time about 10 tidal periods before the desired start of the salinity prediction. The first 10 tidal cycles of calculation will be sufficient to generate water surface elevations and discharges with sufficient accuracy for use as the initial conditions in combination with the known initial salinity distribution.

\section{Longitudinal dispersion}

As noted previously, the local value of the longitudinal dispersion coefficient in Equation (3) represents the combined effect of internal circulation (induced by density (salinity) gradients and boundary shear) on the spatial variation of velocity and salinity at a cross-section. The latter effect is assumed to be represented by a dispersion relation originally formulated by Taylor [14] for turbulent shear flow in pipes. The former effect is assumed to be proportional to the absolute value of the local longitudinal salinity gradient. This assumption implies that density induced circulation is greatest in the region in which the longitudinal salinity gradient is largest. The assumed relationship has the form,

$$
E(x, t)=K\left|\frac{\partial \dot{s}}{\partial \dot{x}}\right|+E_{T}
$$

where, $K$ is a stratification parameter indicating the degree of stratification in the estuary, $\dot{s}=s / s_{0}, x=x / L, L$ being the length of the estuary from the ocean entrance to the head of tide, and $E_{T}$ is the Taylor type dispersion coeffi-

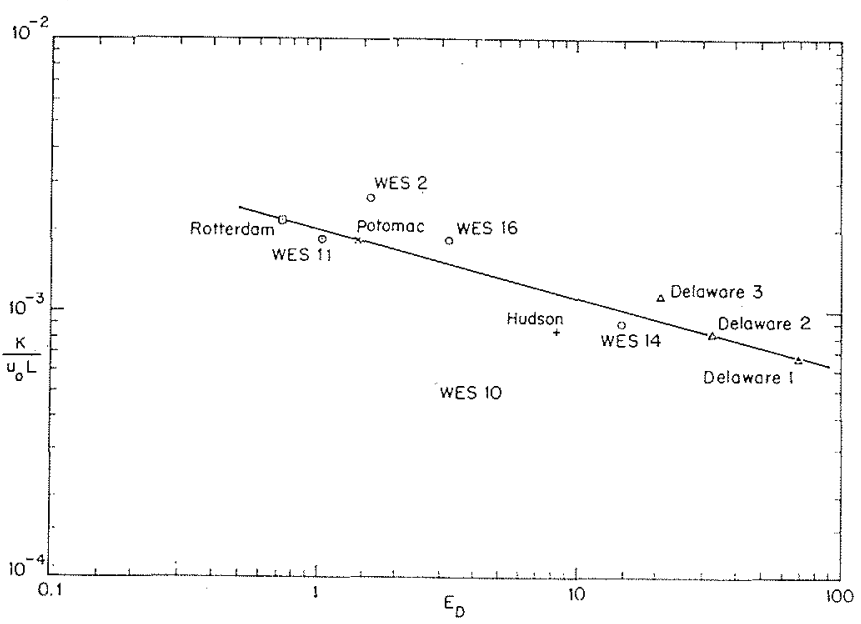

5/ Correlation of normalized stratification parameter with estuary number. cient applicable in the upstream fresh water portion of the estuary where $\partial s / \partial x=0$.

The local salinity gradient is expressed in dimensionless form and the stratification parameter $K$ has the dimensions of a dispersion coefficient, $\left(l^{2} / t\right)$. The stratification parameter $K$ is assumed to be independent of distance and time within a particular tidal period. However, $K$, may vary from one tidal period to the next if the degree of stratification changes. For example, if the fresh water inflow were to increase over a period of a week or more, the estuary would become more stratified and $K$ would increase during the period of time.

The Taylor dispersion relationship in Equation (13), modified for free surface flow [8]:

$$
E_{T}=\frac{20 \sqrt{g}}{C} R_{l l} u
$$

The dispersion function given by Equation (13) when compared to earlier functions such as Equation (10), has several advantages: (1) it contains only one empirical parameter $(K)$, rather than two $\left(E_{0} S L, B\right) ;(2)$ it is not an explicit function of $x$; (3) it is a function of both the longitudinal and vertical gradients of salinity.

In order to make the model completely predictive it is necessary to relate the stratification parameter $K$ to the gross estuary properties which determine the degree of stratification. A modification of the estuary number, Equation (12), is used,

$$
I E_{D}=\frac{P_{t} I F_{D}}{Q_{f} T}
$$

Equation (15) differs from Equation (12) only in that a densimetric Froude number is used in which:

$$
I F_{D}=\frac{u_{0}}{\sqrt{g\left(\Delta \rho_{0} / \rho\right) h}}
$$

where $\Delta \rho_{0}$ represents the density difference between fresh water and ocean water.

Salinity distribution data (from laboratory flumes, estuary models and the field) representing a wide range of physical dimensions and degrees of stratification were employed to determine values of the stratification parameter $K$ under conditions of constant fresh water discharge and repeating ocean tidal elevations. A correlation was found between the normalized stratification parameter $K / u_{0} L$ and the modified estuary number as shown in Figure 5. Note that $u_{0}$ is the maximum flood tide velocity and $L$ is the length of the estuary.

The densimetric estuary numbers, $I E_{D}$, extend over two orders of magnitude ranging from relatively stratified conditions in the Rotterdam Waterway to fairly well-mixed conditions in the Delaware estuary. Within this range the ratio $K / u_{0} L$ varies only by a factor of 5 . By utilizing the correlation of Figure 5, the longitudinal dispersion coefficient is completely determined by Equations (13) and (14) as a function of both local and gross estuary conditions.

\section{Solution technique}

Defining the dispersion coefficient and specifying boundary and initial conditions as discussed above, Equations (1) 
through (4) can be solved by numerical techniques for the dependent variables $h, Q$ and $s$ as functions of $x$ and $t$.

The finite difference scheme used to solve the tidal dynamics equations is similar to that of Harleman and Lee [5] and is a staggered explicit scheme wherein surface elevations and discharges are calculated at alternating locations in the space and time mesh. This scheme has been shown to be efficient in calculation, but the choice of $\Delta x$ and $\Delta t$ must be made in a manner which does not violate the approximate stability criteria,

$$
\Delta t \leqslant \frac{\Delta x}{u+c}
$$

where,

$\Delta x$ and $\Delta t$ are the longitudinal distance and time increments of calculation;

$u$ is the average cross-sectional velocity and $c=\sqrt{g h}$ is the wave speed at the same location as $u$.

The finite difference scheme employed for solution of the salt balance Equation (3) is a six-point implicit scheme based on the minimum error investigation of Stone and Brian [13]. This scheme has a truncation error with terms proportional to $(\Delta x)^{2}$ and $(\Delta t)^{2}$ and is of second order. The truncation error contains no term proportional to $\partial^{2} s / \partial x^{2}$, which means it has no numerical dispersion term as found in some first order schemes (Bella and Grenney [2]).

\section{Application \\ of the mathematical model to the Delawsare estuary}

Predictions of longitudinal salinity distributions during periods of varying fresh water discharge and ocean tidal range have been made for the Delaware, Potomac and Hudson estuaries [6] [15]. A summary of results for the Delaware are presented here to illustrate the application of the mathematical model.

The first step is to schematize the physical dimensions of the estuary to discrete intervals, $\Delta x$, along the longitudinal axis. Each segment of the schematized estuary is represented by either a trapezoidal cross-section or by a rectangular cross-section with an additional area to account for the storage effect of embayments.

If tidal elevation data is available, it can be used to determine the estuary roughness which best reproduces the measured values of tidal elevations along the estuary.

The Delaware estuary has been schematized to $70 \mathrm{sec}-$ tions from the ocean entrance between Cape Henlopen and Cape May to the head of tide at Trenton (see Figure 6). Six sources of fresh water inflow are also shown in Figure 6. The three-month period from August 10th to October 5, 1932 (107 tidal cycles) was selected as the period of study. Inflow hydrographs for the fresh water flow of the major upstream tributaries are shown in Figure 7. The other three tributaries were assigned nominal unvarying flows throughout the study of $82 \mathrm{cfs}$ $\left(2.3 \mathrm{~m}^{3} / \mathrm{s}\right)$ for the Salem River, $132 \mathrm{cfs}(3.7 \mathrm{~m} / \mathrm{s})$

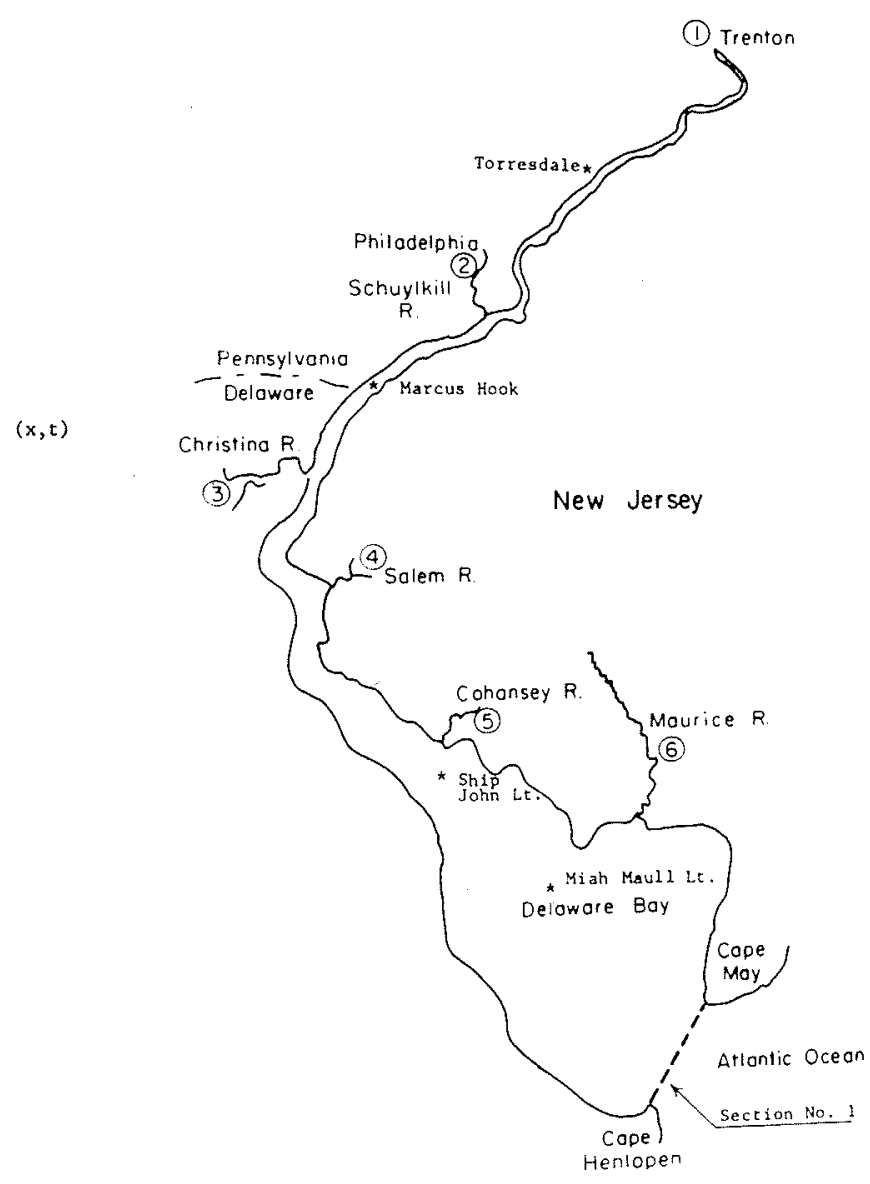

6/ Delaware estuary.

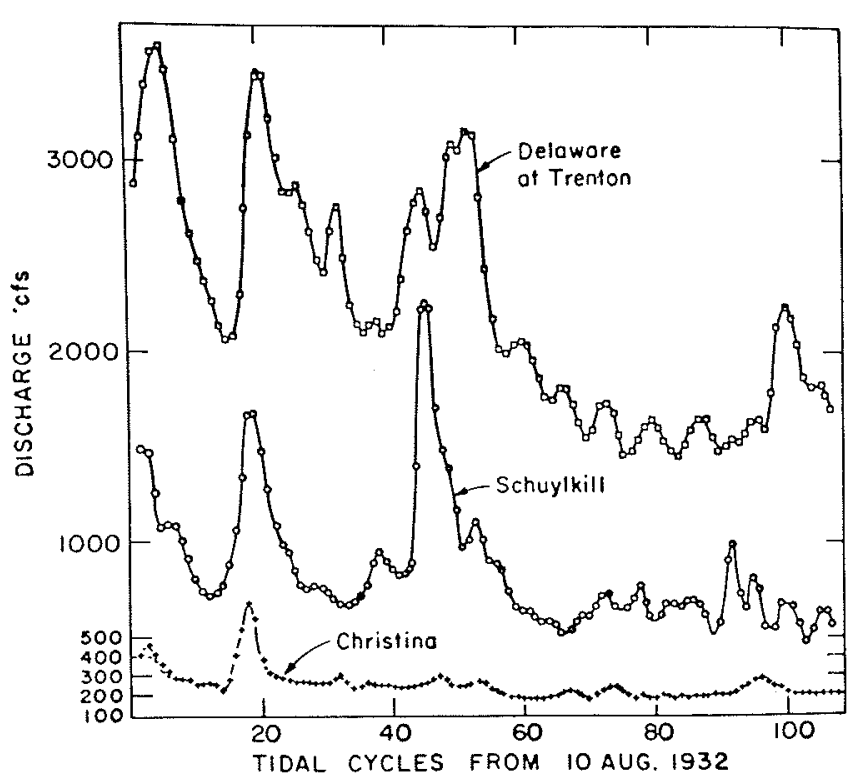

7/ Fresh water inflow to Delaware estuary. 


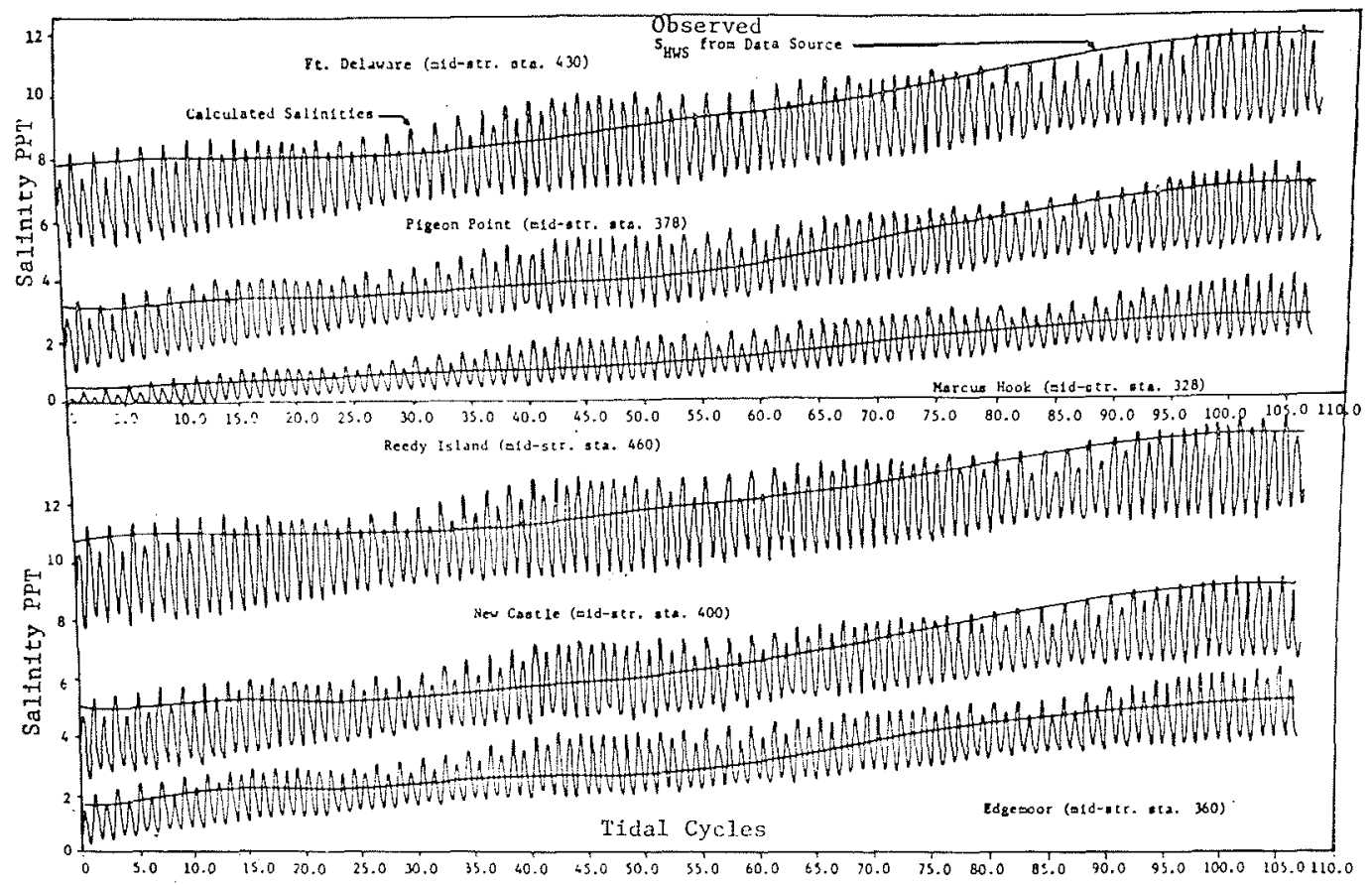

8/ Comparison of computed and observed salinities at six longitudinal stations in the Delaware estuary from 10 August to 5 October, 1932.

for the Cohansey River and 265 cfs $\left(7.5 \mathrm{~m}^{3} / \mathrm{s}\right)$ for the Maurice River. The surface elevations at the ocean entrance were taken from the U.S. Coast and Geodetic Survey Tide Tables, 1932. The tide is semidiurnal and shows monthly spring-neap variations in tidal range from $5.6 \mathrm{ft}(1.7 \mathrm{~m})$ to $2.0 \mathrm{ft}(0.6 \mathrm{~m})$. The ocean salinity, $s_{0}$, was taken as $32 \mathrm{ppt}$ and the tidal period, $T$, as 44,712 seconds. The high water slack isocholars from the Sanitary Water Board, Commonwealth of Pennsylvania for the year 1932 were the source of initial conditions of salinity. The calculation was made for 107 tidal cycles. The predicted salinities at six stations along the estuary are shown as a function of time and are represented by the oscillating curve in Figure 8 .

The only set of field data available during this period for comparison with the output of the mathematical model were those made by the Sanitary Water Board. Salinity measurements were made once each day at high water slack at the six locations along the estuary. The observed high water slack salinities are represented in Figure 8 by a smooth curve. Fresh water inflows during the three-month period are generally decreasing and the results clearly show the trend toward increasing salinity at each of the six stations.

\section{Conclusions}

The numerical model of this study can be used to predict the unsteady Iongitudinal distribution of salinity for partially stratified and mixed estuaries amenable to a one-dimensional representation. This is demonstrated by the successful prediction, over 107 tidal cycles for the Delaware estuary, of the response to changes in both fresh water discharges and ocean tidal amplitudes.
The mathematical model does not require field studies in order to determine the longitudinal dispersion coefficient, but instead utilizes a dispersion coefficient related to the local salinity gradient and the gross parameters expressing the degree of stratification of the estuary. The salinity boundary condition at the ocean entrance is formulated in a manner which depends on the direction of flow at the ocean boundary.

A user's manual (Thatcher and Harleman [16] has been prepared to facilitate application of the numerical model to other estuaries.

\section{References}

[1] Arons (A.B.) and Stommel (H.). -- A mixing-length theory of tidal flushing. Transactions, American Geophysical Union, vol. 32, No. 3 (June 1951).

[2] Bella (D.A.) and Grenney (W.J.). - Finite-difference convection errors. Jounal of the Sanitary Engineering Division, A.S.C.E., vol. 96, No. SA 6 (1970).

[3] Borcourt (W.). - "A numerical model of the salinity distribution in Upper Chesapeake Bay". Technical Report 54, Chesapeake Bay Institute, The Johns Hopkins University (May 1969).

[4] Harleman (D.R.F.) and Abraham (G.). - "One-dimensional analysis of salinity intrusion in the Rotterdam Waterway". Publication No. 44, Delft Hydratics Laboratory (October 1966).

[5] Harlfman (D.R.F.) and LEe (C.H.). - The computation of tides and currents in estuaries and canals. Technical Bulletin No. 16, Committee on Tidal Hydraulics, U.S. Army Corps of Engineers (September 1969). - Also, Appendix A: "A user's manual", by Harleman (D.R.F.) and THaTCHER (M.L.), (June 1973). 
[6] Harleman (D.R.F.), Quinlan (A.V.), Ditmars (J.D.) and Thatcher (M.L.). - "Application of the M.I.T. transient salinity model to the Hudson River Estuary". Report No. 153, Ralph M. Parsons Laboratory for Water Resources and Hydrodynamics, Department of Civil Engineering, M.I.T. (September 1972).

[7] Hol.tey (E.R.) Jr. and Harleman (D.R.F.). - "Dispersion of polluants in estuary type flows ". Report No. 74, Hydrodynamics Laboratory, Department of Civil Engineering, M.I.T. (January 1965).

[8] Holley (E.R.), Harleman (D.R.F.) and Fischer (H.B.). Dispersion in homogeneous estuary flow. Journal of the Hydraulics Division, A.S.C.E., vol. 96, No. HY 8, Proc. paper 7488, pp. 1691-1709 (August 1970).

[9] IPPEN (A.T.) and Harleman (D.R.F.) - "One-dimensional analysis of salinity intrusion in estuaries". T.B. No. 5, Committee on Tidal Hydraulics, U.S. Army, Corps of Engineers (June 1961).

[10] OKuBo (A.). - Equations describing the diffusion of an introduced polluant in a one-dimensional estuary. "Studies in Oceanography", pp. 216-226. University of Tokyo Press.

[11] Pritchird (D.W.). - "Computation of the longitudinal salinity distribution in the Delaware Estuary for various degrees of river inflow regulation". Technical Report XVIII, Chesapeake Bay Instilute, The Johns Hopkins University (September 1959).

[12] Stigter (C.) and Siemons (J.). - "Calculation of longitudinal salt distribution in estuaries as function of time". Publication No. 52, Delft Hydraulic Laboratory (October 1967).

[13] Stonse (H.L.) and BrinN (P.L.T.). - Numerical solution of convective transport problems. Journal of the American Institute of Chemical Engineers, vol. 9, No, 5 (September 1963).

[14] TAYLOR (G.I.). - The dispersion of matter in turbulent flow through a pipe. Proceedings, Royal Society of London, series A, vol. 223, No. 1155, pp. 446-468 (May 1954).

[15] Thatcher (M.L.) and Harleman (D.R.F.). - "A mathematical model for the prediction of unsteady salinity intrusion in estuaries". Report No, 144, R.M. Parsons Laboratory for Water Resources and Hydrodynamics, Department of Civil Engineering, M.I.T. (February 1972).

[16] Thatcher (M.L.) and Harleman (D.R.F.). - "Prediction of unsteady salinity intrusion in estuaries: Mathematical model and user's manual". Report No. 159, R.M. Parsons Laboratory for Water Resources and Hydrodynamics, Department of Civil Engineering, M.I.T. (November 1972).

\section{Discussion}

Président : M. M. Hug

M. le Président remercie chaleureusement $M$. le Professeur HARLEMAN pour son exposé très synthétique et particulièrement suggestif; il ouvre ensuite la discussion.

M. le Président Banal souhaiterait voir préciser la signification de la « ligne noire» qu figure sur les premiers graphiques présentés; elle semble donner les valeurs maximales mesurées de la salinité; comment se place-t-elle par rapport à la courbe représentant la vraie variation périodique de la salinité ?

Réponse de M. le Professeur Harueman :

The smooth curve in Figure 8 represents the salinities measured at high water slack once each day. Unfortunately the data records did not indicate at which of the two possible times of high water slack in a given calendar day the observations were made. Therefore, it is impossible to indicate in the graph the exact time at which the field measurements were made. As a general rule, salinities at high water slack are the maximum values observed within a tidal period at a given location.

Se référant aux mêmes graphiques, M. Mauvars (Centre Océanologique de Bretagne, Brest), souhaiterait que soient expliquées les différences d'amplitude (vers le haut et vers le bas) des différents cycles. A priori, on s'attendrait à des oscillations de même amplitude.

Réponse de M. le Professeur Harleman :

The differences in the amplitudes of the calculated salinities from one tidal period to the next are primarily a result of amplitude differences in the semi-diurnal tide at the ocean entrance to the estuary. The longitudinal motion of salinity distribution within one tidal cycle is largely governed by the ocean tide which drives the tidal motion in the entire estuary.

Quelles est la formulation du nombre d'estuaire demande M. Allen?

Réponse de $M$. le Professeur Harleman :

Equations (15) and (16) define the "estuary number".

M. VReugdenHIL (Laboratoire d'Hydraulique de Delft) intervient ensuite en ces termes :
The correlation between the dispersion coefficient $K$ and the estuary number $E_{D}$ shows a considerable scatter. What would be the sensitivity of the numerical results for salinity intrusion to a variation by a factor of, say, 2 of the coefficient $K$ ?

Réponse de $M$. le Professeur Harteman :

For transient cases in real estuaries in which fresh water inflow and ocean tides are changing, the numerical results are not sensitive to a variation in $K$ by a factor of 2 . Under hypothetical conditions of constant fresh water inflow and a repeating ocean tide, a quasi-steady state salinity intrusion may be reached alter 100 or more tidal cycles. I would expect a significant change in this quasi-steady salinity distribution if $K$ were changed by factor of 2 .

Is the same value of $E$ that is to say :-

$$
\left.E=K\left[\delta\left(C / C_{i 0}\right) / \delta(x / L)\right]\right\}
$$

used fort salt, heat, B.O.D. etc ? ask M. ABRAHAM.

Réponse de M. le Professeur Harleman :

If heated water or sewage containing B.O.D. were introduced more or less uniformly over the cross-section of an estuary by means of a diffuser, I expect the same local value of $E$ would be appropriate. In this case buoyancy effects would be small and the heated water or sewage would participate in the general salinity induced longitudinal dispersion process.

If, on other hand, the heat or sewage is introduced into the estuary as a concentrated source, one must consider the jet induced mixing and buoyancy of the source in the near-ficld region. In this case the problem is no longer susceptible to one-dimensional analysis.

En l'absence d'autre demande d'intervention, $M$. le Président clôt la discussion en remerciant toutes les personnes qui l'ont animée. Il donne ensuite la parole à M. MALHerbe pour la présentation de la communication qu'il a préparée en collaboration avec M DAubert. 